\title{
BOND STRENGTH OF RESIN MODIFIED GLASS IONOMER CEMENT TO PRIMARY DENTIN AFTER CUTTING WITH DIFFERENT BUR TYPES AND DENTIN CONDITIONING
}

\author{
Rebeca DI NICOLÓ ${ }^{1}$, Luciana Keiko SHINTOME², Silvio Issáo MYAKI ${ }^{1}$, Marcos Paulo NAGAYASSU ${ }^{2}$
}

\author{
1- PhD,Assistant Professor, Department of Pediatric Dentistry, School of Dentistry of São José dos Campos, State University of São Paulo \\ (UNESP), São José dos Campos, SP,Brazil. \\ 2- MSc, Graduate Student, Department of Restorative Dentistry, School of Dentistry of São José dos Campos, State University of São Paulo \\ (UNESP), São José dos Campos, SP,Brazil.
}

Corresponding address: Dra. Luciana Keiko Shintome - R. Capitão Teófilo, 63 apto. 51-B - Centro, Cep: 07011-050 - Guarulhos, SP, Brasile-mail: lushintome@ig.com.br

Received: December 15, 2006- Modification: May 30, 2007 - Accepted: August 21, 2007

\begin{abstract}
$T_{\text {he }}$

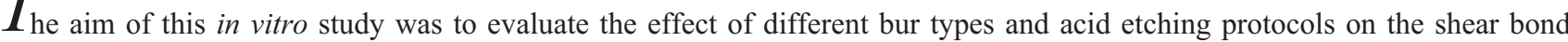
strength (SBS) of a resin modified glass ionomer cement (RM-GIC) to primary dentin. Forty-eight clinically sound human primary molars were selected and randomly assigned to four groups $(\mathrm{n}=12)$. In $\mathrm{G} 1$, the lingual surface of the teeth was cut with a carbide bur until a 2.0-mm-diameter dentin area was exposed, followed by the application of RM-GIC (Vitremer - 3M/ESPE) prepared according to the manufacturer's instructions. The specimens of G2, received the same treatment of G1, however the dentin was conditioned with phosphoric acid. In groups G3 and G4 the same procedures of G1 and G2 were conducted respectively, nevertheless dentin cutting was made with a diamond bur. The specimens were stored in distilled water at $37^{\circ} \mathrm{C}$ for $24 \mathrm{~h}$, and then tested in a universal testing machine. SBS. data were submitted to 2-way ANOVA $(=5 \%)$ and indicated that SBS values of RM-GIC bonded to primary dentin cut with different burs were not statistically different, but the specimens that were conditioned with phosphoric acid presented SBS values significantly higher that those without conditioning. To observe micromorphologic characteristics of the effects of dentin surface cut by diamond or carbide rotary instruments and conditioners treatment, some specimens were examined by scanning electron microscopy. Smear layer was present in all specimens regardless of the type of rotary instrument used for dentin cutting, and specimens etched with phosphoric acid presented more effective removal of smear layer. It was concluded that SBS of a RM-GIC to primary dentin was affected by the acid conditioning but the bur type had no influence.
\end{abstract}

Uniterms: Glass ionomer cements, modified; Dental instruments; Dentin; Prymary teeth, conditioning.

\section{INTRODUCTION}

One of the major challenges in dentistry has been to find an ideal restorative material that has physical properties similar to those of tooth structure, adhesion to dentin and enamel, in addition to resistance to degradation in the oral cavity ${ }^{27}$. In attempt to reach these characteristics, glass ionomer cement (GIC) was developed and first presented by Wilson and $\mathrm{Kent}^{29}$ in 1972 . Its initial formulation underwent several modifications with the intent to improve handling and its physical properties.

A remarkable improvement of this class of material occurred approximately 15 years ago, with the introduction of the resin-modified glass ionomer cement (RM-GIC). This material is characterized by the addition of photo-activated methacrylate, and a small amount of resin, such as 2-HEMA or bisphenol-A-glycidyl methacrylate (Bis-GMA), to the conventional glass ionomer cement (GIC) liquid or powder ${ }^{14}$. At the present time, RM-GICs present two or three setting reactions: a) acid-base reaction, typical of conventional GICs (initiated when the powder and liquid are mixed, occurring without light); b) photoinitiated setting reaction through the methacrylate groups (initiated when the powder/liquid mixture is exposed to light and occurs only where the light penetrates); c) free-radical methacrylate curing without light (initiated when the powder and liquid are mixed without necessity of light) ${ }^{26}$.

During cavity preparation, tooth structure is cut by rotary 
or manual instruments and a large amount of energy is generated locally, which results in denatured collagen and chemically and physically altered surfaces. This procedure produces smear layer, which can influence the adhesion between the tooth structure and dental materials ${ }^{8}$. Brännström, et al. ${ }^{4}$ (1979) has reported that there is a micromorphologic difference between dentin cut by diamond and carbide rotary instruments. The surfaces cut with diamond burs examined by scanning electron microscope presented more irregularities and thicker smear layer when compared to the dentin surface cut with carbide burs.

One of the main characteristics of GICs is their adhesion to tooth structure. An intimate contact between the dental material and its substrate is necessary to create an effective adhesion. For such purpose, various conditioning agents that remove or modify the smear layer have been used in order to improve the adhesion and clinical results of this material ${ }^{27}$.

Regarding the conventional GICc, citric acid was one of the first conditioning solutions used to treat the dentin surface, but it was not frequently used because it had low biocompatibility and did not increase the bond strength between the material and tooth structure ${ }^{20}$. Polyacrylic acid is one of the most used pre-treatment substances after cavity preparation and promotes an increase in the bond strength between the conventional GICs and dentin ${ }^{11,13}$.

Many cleaning solutions, such as polyacrylic acid and phosphoric acid in different concentrations have been investigated as a pre-treatment to RM-GICs, in order to improve their adhesion to the dentin surface ${ }^{9,17,18,21}$. Dentin conditioning can act differently on RM-GICs due to the presence of resin components that can infiltrate into the demineralized dentin and after polymerized result in micromechanical retention ${ }^{6}$.

Studies comparing the shear bond strength of RM-GICs to primary dentin after cutting with different bur types with or without prior conditioning with phosphoric acid have not found in the surveyed full-text electronic databases (Medline and Lilacs).

The purpose of this in vitro study was to evaluate the shear bond strength of a RM-GIC to primary dentin, after cutting with diamond or carbide rotary instruments with or without phosphoric acid conditioning.

\section{MATERIAL AND METHODS}

Forty-eight clinically sound primary molars were used in this study. The teeth were obtained from the Pediatric Dentistry Clinic at the School of Dentistry of São José dos Campos -UNESP after their natural exfoliation; approved by the Ethical in Research Committee (protocol \#006/2003-PH/ CEP).

Tissue remnants and debris were removed with periodontal curettes. The teeth were stored in $0.5 \%$ chloramine solution for one week and later in distilled water at $4{ }^{\circ} \mathrm{C}$. The teeth were embedded in self-cured acrylic resin, obtaining $2.0 \mathrm{~cm}$ large $\mathrm{x} 2.0 \mathrm{~cm}$ thick specimens. The teeth were randomly assigned to four groups $(n=12)$ according to the cutting rotary instrument used and dentin treatment received.

In group 1, the lingual dentin surface was exposed using a high-speed carbide rotary instrument (\# H21L.314.014; Komet, Germany) under copious water irrigation, and then cleaned with pumice/water slurry in rubber cups. The surface was rinsed with water and gently air dried. Vitremer primer (3M/ESPE) was applied for $30 \mathrm{~s}$, gently air dried and light cured for $20 \mathrm{~s}$.

In group 2, the specimens had the lingual dentin surface exposed by using a high-speed carbide rotary instrument (\# H21L.314.014; Komet; Germany) under copious water irrigation, and then cleaned with pumice/water slurry in rubber cups. The surface was rinsed with water and gently air dried. After this procedure, dentin was conditioned with $35 \%$ phosphoric acid (Etchant; 3M/ESPE, St. Paul, MN, USA) for $15 \mathrm{~s}$, rinsed for $30 \mathrm{~s}$ and blotted with a filter paper. Vitremer primer was applied for $30 \mathrm{~s}$, gently air dried and light cured for $20 \mathrm{~s}$.

Groups 3 and 4 received the same treatment as those described groups 1 and 2, respectively, but dentin cutting was made with a diamond bur (\# 836KR.314.014;Komet, Germany).

In all groups, a high-speed turbine attached to a device was used for standardized dentin preparation. Dentin was cut until a 2.0-mm dentin area was exposed.

The surface area to be treated was isolated with a vinyl tape with a 2.0 -mm-diameter hole. The specimens were placed in a split bisected Teflon matrix with a 2.0-mm-diameter cavity where the RM-GIC Vitremer (3M/ESPE, St. Paul, MN, USA) was inserted following the manufacturer's instructions.

Vitremer was light cured for $40 \mathrm{~s}$ and chemically cured for $4 \mathrm{~min}$. The matrix was removed carefully obtaining a $2.0 \times 2.0 \mathrm{~mm}$ RM-GIC cylinder. The specimens were stored in distilled water at $37^{\circ} \mathrm{C}$ for 24 hours, and thereafter, submitted to mechanical tests. Shear bond strength was measured in an Instron universal testing machine (Model 4301; Instron, Norwood, MA, USA) with a $500 \mathrm{~kg}$ load cell at a crosshead speed of $0.5 \mathrm{~mm} / \mathrm{min}$.

In order to observe the micromorphologic characteristics of dentin surface cut by diamond or carbide rotary instruments and treated or not by conditioners, three specimens were prepared according to the specifications for groups 1 to 4 and dehydrated in increasing ethanol concentrations $(70 \%, 80 \%, 90 \%$ and $100 \%)$, mounted in metallic stubs and covered with gold for evaluation under the SEM. The data from the shear bond test was submitted to two-way ANOVA and Tukey's test ( $p=0.05$ ).

\section{RESULTS}

Table 1 and Figure 1 shows that the groups that did not receive conditioning presented the lowest resistance to shear bond strength.

Table 2 (ANOVA test) demonstrates the possibility of 
rejecting the hypothesis that either conditioning or not dentin leads to equal results $(\mathrm{p}=0.05)$. On the other hand, there is a possibility of not rejecting the hypothesis of an equal effect between the different cutting rotary instruments used, in addition to the interaction of the instrument with the dentin surface conditioner. (Table 2)

In Figure 2, the RM-GIC bond strength to dentin is higher when $35 \%$ phosphoric acid conditioner is used than without the conditioner application.

The SEM micrographs revealed the formation of smear layer in all specimens, regardless of the type of rotary instrument used for dentin cutting. It is suggested that cutting of dentin surface with the diamond bur (Fig. 3b) created a thicker layer of debris when compared to the carbide bur (Fig. 3a).

Figures $4 \mathrm{a}$ and $4 \mathrm{~b}$ show dentin surfaces cut by rotary instruments and conditioned with $35 \%$ phosphoric acid for $15 \mathrm{~s}$. Complete removal of the smear layer and open dentinal tubules can be observed. The dentin surface cut by diamond bur (Fig. 4b) appears more irregular when compared to surfaces cut by carbide bur (Fig. 4a).In figure 5, the effect of Vitremer primer can be observed on the prepared surfaces. Vitremer primer partially removed the smear layer leaving the tubules obliterated.

\section{DISCUSSION}

The adhesion of dental materials to dentin has been extensively investigated in the last decades in order to make it effective and durable, but due to dentin complexity this is

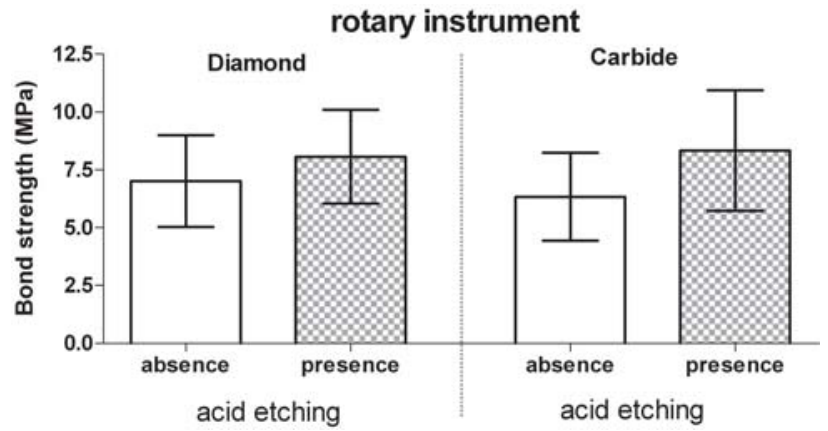

FIGURE 1- Shear bond strength means (MPa) and standard deviation by type of instrument (diamond and carbide) and acid etching (presence and absence)

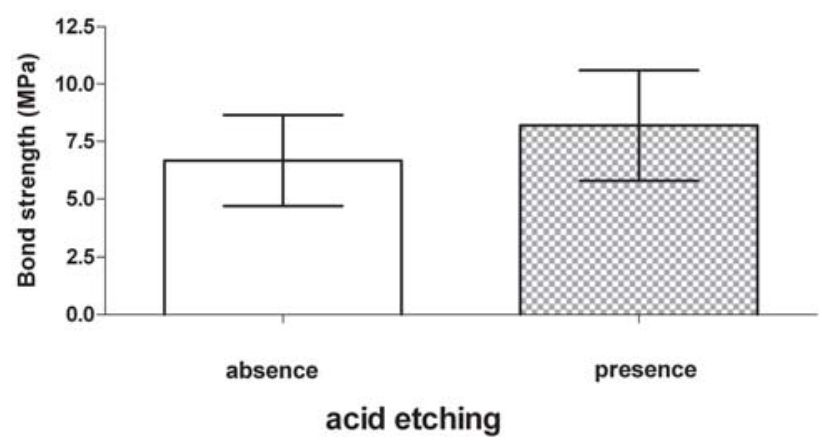

FIGURE 2- Shear bond strength means (MPa) and standard deviation by type of acid etching (presence and absence) without instrument effect

TABLE 1- Descriptive statistics for shear bond strength data (MPa) obtained by type of instrument (diamond and carbide) and acid etching (presence and absence)

\begin{tabular}{|c|c|c|c|c|}
\hline \multirow[t]{2}{*}{ Statistics } & \multicolumn{2}{|c|}{ Diamond bur } & \multicolumn{2}{|c|}{ Carbide bur } \\
\hline & absence & presence & absence & presence \\
\hline $\mathrm{N}$ & 12 & 12 & 12 & 12 \\
\hline Minimum & 3.60 & 4.23 & 3.31 & 4.44 \\
\hline Maximum & 10.56 & 11.81 & 11.82 & 12.78 \\
\hline Mean & 7.01 & 8.07 & 6.33 & 8.33 \\
\hline Standard deviation & 1.98 & 2.03 & 1.90 & 2.61 \\
\hline
\end{tabular}

TABLE 2- Bond strength means for the test groups (ANOVA, $p=0.05$ )

\begin{tabular}{lcccc}
\hline Effects & degree of freedom (df) & sum square (ss) & mean square (MS) & p \\
\hline Acid etching & 1 & 27.9350 & 27.9350 & 0.0180 \\
Instrumentation & 1 & 0.52710 & 0.52710 & 0.7373 \\
Interaction & 1 & 2.66963 & 2.66963 & 0.4514 \\
Error & 44 & 203.490 & 4.62478 & \\
Total & 47 & & & \\
\hline
\end{tabular}


an arduous procedure ${ }^{24}$. Unlike enamel, dentin is a live, dynamic tissue that contains greater portion of water and organic material. It is connected to the pulp through the dentinal tubules, which extend from the pulp to the dentinoenamel junction. These tubules contain dentinal fluid

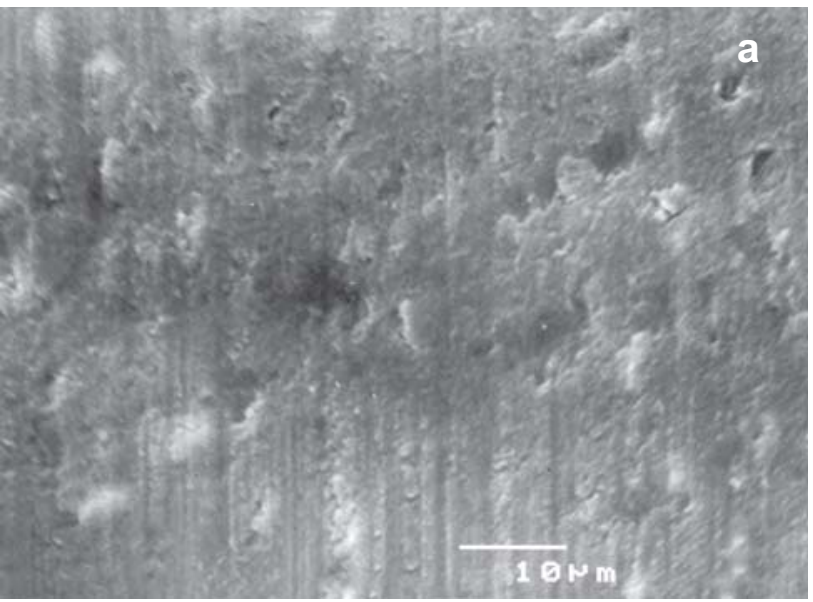

that is responsible for the intrinsic humidity of this structure 10,24

Different mechanical tests have been proposed to asses the bonding performance of restorative materials. Although it suffers criticism, shear testing has been widely used to

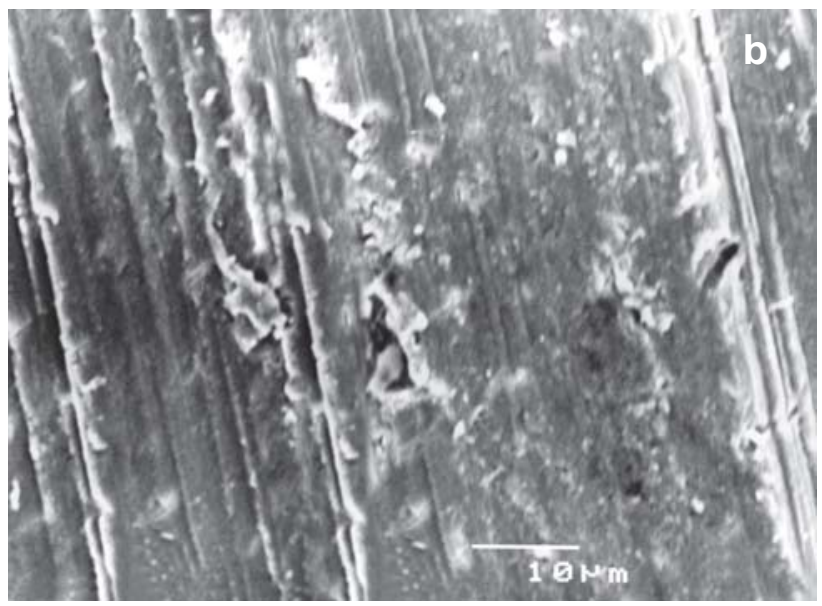

FIGURE 3- Dentin surface cut by: a) carbide bur; b) diamond bur. (Original magnification 1500X, bar=10 $\mu \mathrm{m}$ )
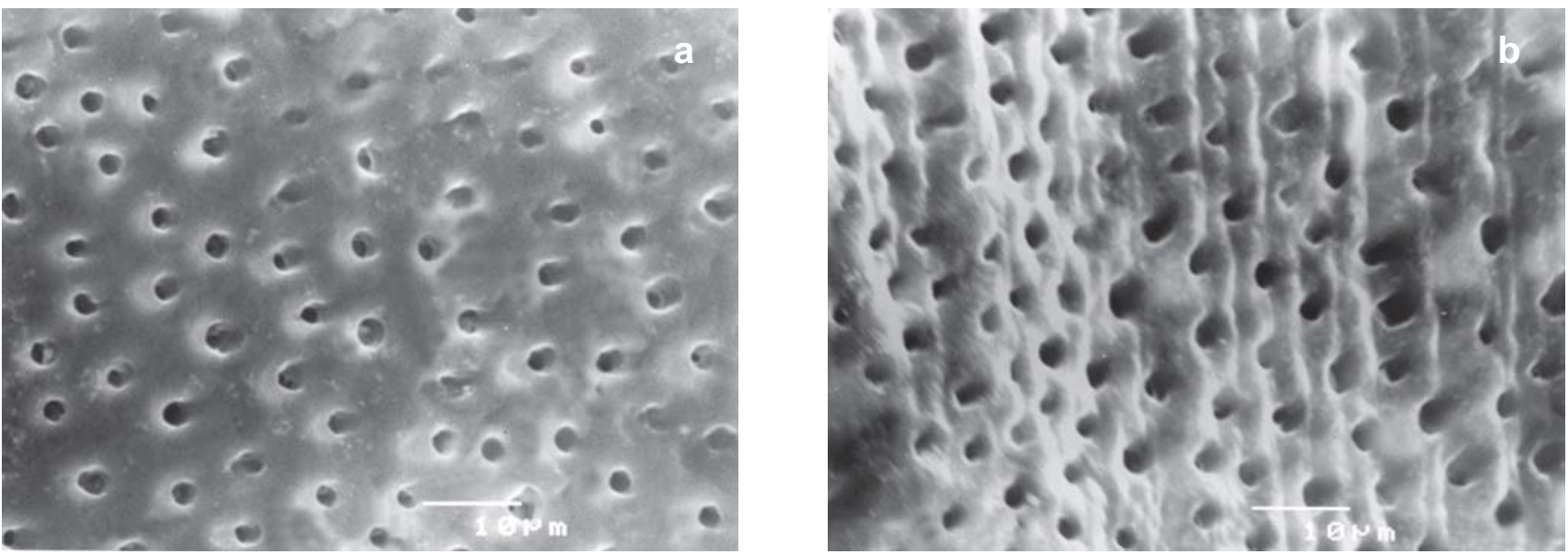

FIGURE 4- Dentin surface cut by: a) carbide bur after $37 \%$ phosphoric acid etching; b) diamond bur after $37 \%$ phosphoric acid etching (Original magnification 1500X, bar=10 $\mu \mathrm{m}$ )
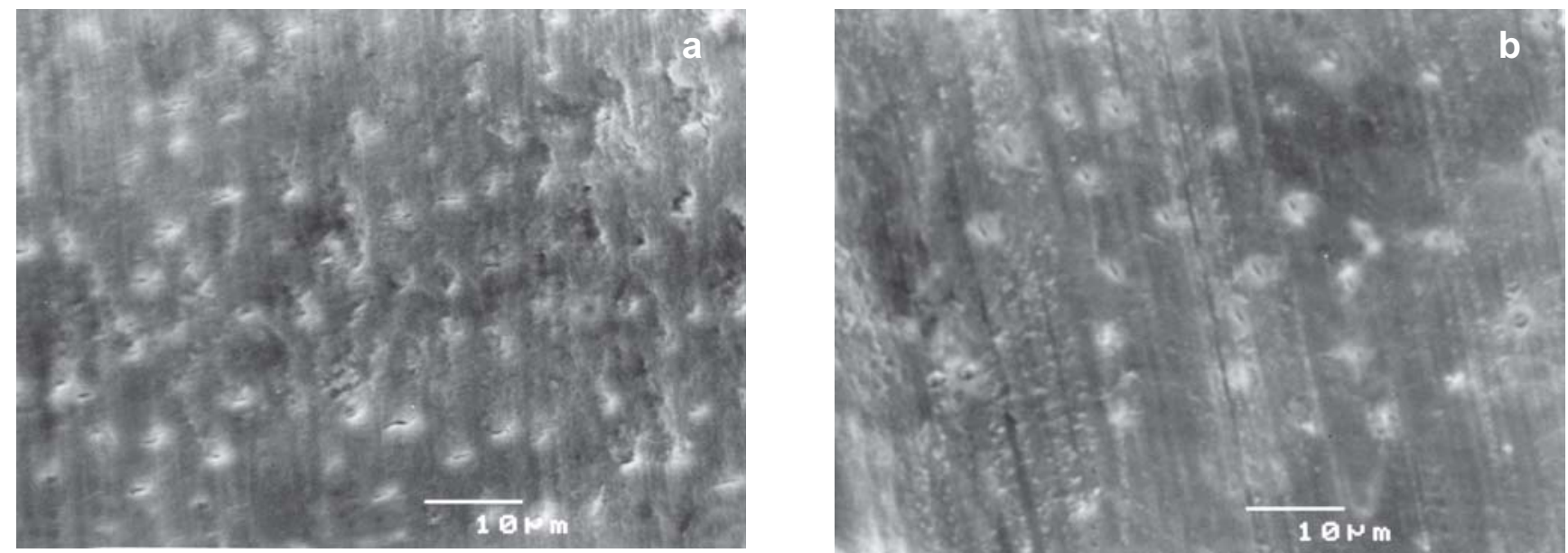

FIGURE 5- Dentin surface cut by: a) carbide bur after conditioning with Vitremer primer; b) diamond bur after conditioning with Vitremer primer (Original magnification 1500X, bar=10 $\mu \mathrm{m}$ ) 
evaluate the bonding ability of adhesive materials to dental structure $^{18,19}$. Particularly regarding GICs, which present low bond strength, other tests may be difficult to apply ${ }^{28}$. The bond strength RM-GICs to dentin have been reported as higher than that of conventional GICs ${ }^{3,7}$. However, the accurate mechanism of adhesion of this material is not completely established. Some SEM studies revealed the formation of tags at the dentin-cement interface resultant from the RM-GIC polymer penetration into the dentinal tubules ${ }^{1,17,19}$.

In the present study, SEM observation showed the micromorphologic differences on the surfaces cut by diamond or carbide rotary instruments. SEM analysis suggests that specimens prepared with diamond bur presented a more irregular dentin surface with a visible thicker smear layer when compared to the carbide bur group (Figs. 3 and 4). These findings agree with those of previous reports $4,8,12,22$.

The use of both rotary instruments produces different topographic characteristics on dentin surface (Fig. 4), which can affect the bond strength between dental material and prepared surface ${ }^{22}$. Nevertheless, some studies ${ }^{15,25}$ observed that dentin surface cut with different instruments did not influence the bond strength and this result corroborates with ours. The outcomes of this study demonstrate that the shear bond strength means of the surfaces prepared with carbide bur (groups 1 and 2) or diamond bur (group 3 and 4) to the RM-GIC were not statistically different (Table 2).

The presence of smear layer on dentin surfaces restrains the effective contact between restorative material and dental tissue impairing a satisfactory adhesion ${ }^{12}$. With the RMGIC improvement some authors suggested that dentin surface should be treated with agents that promote smear layer removal or modification. This procedure tends to improve resin monomer (HEMA) penetration, into the dentinal tubules, thus creating micromechanical retention and improving the adhesion ${ }^{3,6,7,17,19,28}$.

Different conditioners have been investigated to improve the clinical performance of RM-GICs ${ }^{17,18}$. Some studies consider that the effect of Vitrebond liquid is similar to that of some adhesive systems ${ }^{11}$. Other investigations observed an improvement in RM-GIC bond strength when enamel conditioning with phosphoric acid was done ${ }^{5,11,23}$. Therefore, this study used $35 \%$ phosphoric acid as dentin conditioner prior to the RM-GIC application.

Groups 2 and 4, with phosphoric acid conditioning, presented the highest shear bond strength means (Fig. 1 and Table 2). It can be suggested in these groups that the effective removal of smear layer, exposure of collagen network and opening of dentinal tubules promoted a better resin monomer (HEMA) penetration within the underlying dentin, thus creating a hybrid layer. This fact increases the surface energy and contributes to provide a better moisture of dentin surface creating an interdiffusion zone between cement and dentin matrix, which contributes to micromechanical retention, in addition to the RM-GIC chemical adhesion to dentin ${ }^{16,17,18}$.

The lowest shear bond strength means were found in groups 1 and 3, which received only the Vitremer primer, following the manufacturer's recommendations. The SEM micrographs of dentin surface treated with Vitremer primer revealed a partial removal of smear layer (Fig. 5). An amorphous structure remained covering the dentinal tubules; this fact is in accordance to other studies in the literature ${ }^{1,7}$. The Vitremer primer's $\mathrm{pH}$ is not low enough to completely remove the smear layer from dentin surface. Therefore it prevents the penetration of resin material into dentinal tubules and formation of an interdiffusion zone which is related to micromechanical adhesion between the cement and underlying dentin matrix ${ }^{2,16}$.

According to the results of this study, dentin conditioning with $35 \%$ phosphoric acid prior to RM-GIC application was able to improve adhesion between this material and dentin (Fig 2). Comparison to other studies was not possible due to lack of previous investigations. This finding can be very appropriate because the use of adhesive systems to improve bond strength was not necessary, which may be an advantage as the adhesive system could have formed a barrier at this interface preventing the diffusion of fluoride ions into dentin ${ }^{16,28}$. Nevertheless, further research should be performed in order to observe the dentin/RM-GIC interface after phosphoric acid conditioning and investigate whether it can interfere with fluoride ion release, thus jeopardizing GIC anticaries effect.

\section{CONCLUSIONS}

According to the methodology used in this study and the statistical analysis obtained, it was concluded that early shear bond strength of RM-GIC to primary dentin was affected by the acid conditioning, but the different bur types used in this study had no influence.

\section{ACKNOWLEDGEMENTS}

The authors acknowledge Professor Ivan Balducci for his assistance with the statistical analysis.

\section{REFERENCES}

1- Abdalla AI. Morphological interface between hybrid ionomers and dentin with or without smear-layer removal. J Oral Rehabil. 2000;27(9):808-14.

2- Abdalla AI, García-Godoy F. Bond strengths of resin-modified glass ionomers and polyacid-modified resin composites to dentin. Am J Dent. 1997;10(6):291-4.

3- Almuammar MF, Schulman A, Salama F. Shear bond strength of six restorative materials. J Clin Pediatr Dent. 2001;25(3):221-5.

4- Brännström M, Glantz PO, Nordenvall KJ. The effect of some cleaning solutions on the morphology of dentin prepared in different ways: an in vivo study. ASDC J Dent Child. 1979;46(4):291-5. 
5- Briso ALF, Sundfeld RH, Mauro SJ, Holland Júnior C, Sundfeld, MLMM, Nani FF. Avaliação da infiltração marginal em restaurações cervicais com ionômero de vidro fotopolimerizável: efeitos de tratamentos superficiais do esmalte e dentina. Rev Bras Odontol. $1998 ; 55(3): 153-9$.

6- Burrow MF, Nopnakeepong U, Phrukkanon S. A comparison of microtensile bond strengths of several dentin bonding systems to primary and permanent dentin. Dent Mater 2002;18(3):239-45.

7- Chain MC, Chain J B, Leinfelder K F. Cimentos ionoméricos híbridos: força de adesão à dentina e mecanismo de união. Uso da microscopia eletrônica. RGO (Porto Alegre). 2000;48(1):42-9.

8- Eick JD, Johnson LN, Wilko AR, Anderson CH, Sorensen SE. Scanning electron microscopy of cut tooth surfaces and identification of debris by use of the electron microprobe. J Dent Res. 1970;49(6):1359-68.

9- Erickson RL, Glasspole EA. Bonding to tooth structure: a comparison of glass-ionomer and composite resin systems. J Esthet Dent. 1994;6(5):227-44

10- Garberoglio R, Brännström M. Scanning electron microscoic investigation of human dental tubules. Archs Oral Biol 1976;21(6):355-62

11 - Glasspoole EA, Erickson RL, Davidson CL. Effect of surface treatments on bond strength of glass ionomers to enamel. Dent Mater. 2002;18(6):454-62.

12 - Gwinnett AJ. Smear layer: morphological considerations. Oper Dent. 1984;9(3):3-12.

13 - Joynt RB, Davis EL, Wieczkowski G, Pierce 1. Effect of dentinal pretreatment on bond strength between glass ionomer cement and dentin. Oper Dent. 1990;15(5):173-7.

14- Mathis R, Ferracane JL. Properties of a glass-ionomer/resincomposite hybrid material. Dent Mater. 1989;5(5):355-8.

15- McInnes PM, Wendt S.Jr, Retief DH, Weinberg R. Effect on dentin surface roughness on shear bond strength. Dent Mater. 1990;6(3):204-7.

16- Miyazaki M, Iwasaki K, Onose H, Moore BK. Resin-modified glass-ionomers: effect of dentin primer application on the development of bond strength. Eur J Oral Sci. 1999;107(5):393-9.

17- Nakanuma K, Hayakawa T, Tomita T, Yamazaki M. Effect of the application of dentin bonding agent on the adhesion between the resin-modified glass-ionomer cement and dentin. Dent Mater. $1998 ; 14(4): 281-6$.

18 - Pereira PNR, Yamada T, Inokoshi S, Burrow MF, Sano H, Tagami J. Adhesion of resin-modified glass ionomer cements using resin bonding systems. J Dent. 1998;26(5-6):478-85.

19- Pereira PNR, Yamada T, Tei R, Tagami J. Bond strength and interface micromorphology of an improved resin-modified glass ionomer cement. Am J Dent. 1997;10(3):128-32.

20 - Powis DR, Folleras T, Merson AS, Wilson AD. Improved adhesion of a glass ionomer cement to dentin and enamel. J Dent Res. 1982;61(12):1416-22.

21 - Prati C, Montanari G, Biagin G, Fava F, Pashley DH. Effects of dentin surface treatments on shear bond strength of Vitrabond. Dent Mater. 1992;8(1):21-6.

22- Sattabanasuk V, Vachiramon V, Qian F, Armstrong SR. Resindentin bonding strength as related to different surface preparation methods. J Dent. 2007;35(6): 467-75
23 - Sundfeld RH, Komatsu J, Mauro SJ, Holland Junior C, Hoeppner MG. Selamento oclusal com ionômero de vidro fotopolimerizável uma proposta altamente eficaz na prevenção da cárie dental. Âmbito Odontol. 1994;3:3-7.

24- Swift Junior EJ, Pawlus MA, Vargas, MA. Shear bond strength of resin-modified glass ionomer restorative materials. Oper Dent. $1995 ; 20(4): 138-43$

25- Tagami J, Tao L, Pashley DH, Hosoda H, Sano H. Effects of high-speed cutting on dentin permeability and bonding. Dent Mater. 1991;7(4):234-9.

26-3M. Produtos Dentários. 3M Vitremer. Ionômero de ativação tripla: perfil técnico do produto. Campinas: 3M do Brasil; 1994. 34p.

27 - Walls AWG. Glass polyalkenoate (glass ionomer) cements: a review. J Dent. 1986;14(6):231-46.

28- Wang L, Sakai VT, Kawai ES, Buzalaf MAR, Atta MT. Effect of adhesive systems associated with resin-modified glass ionomer cements. J Oral Rehabil. 2006; 33(2):110-6.

29- Wilson AD, Kent BE. A new translucent cement for dentistry: the glass ionomer cement. Br Dent J. 1972;15(4):133-5. 